\title{
Respon dan Tanggapan Siswa terhadap Komponen dan Kegiatan Pembelajaran Matematika Menerapkan Pendekatan Eksplorasi-Elaborasi-Konfirmasi (EEK)
}

\author{
Sripatmi ${ }^{* *}$, Ratna Wahyu Ningsih ${ }^{2}$ \\ 1,2 Pendidikan Matematika, FKIP, Universitas Mataram, Mataram \\ *email: spatmi@gmail.com
}

\begin{abstract}
The study aims at elaborating the students' responses towards the components and implementation of learning activities using EEK (Exploration - Elaboration - Confirmation) approach. Based on the observation during the lesson, it was found that: (i) most of the students were seriously hearing the information and answering the teacher's questions, (ii) curious to work on the students' worksheets (LKS and LLS), (iii) looking at the presenter when their classmates present the task and when the teacher gives clarification or feedback. Moreover, based on the students' responses in answering the questionnaire related to the activities, it was found that: (i) more than $60 \%$ stated their positive feedback toward the lesson and the new approach of teaching (ii) more than $60 \%$ students stated their positive feedback toward the learning media, (iii) most of the students agreed that the task was easy, (iv) 85,3\% students stated the positive responses toward the learning approach and (v) 100\% students stated their agreement that mathematics is useful for their daily life. From the result, it can be concluded that the students positively react to the implementation of EEK approach in mathematics classroom.
\end{abstract}

Keywords: EEK; LKS; LLS

\begin{abstract}
Abstrak
Tujuan penelitian ini adalah mengetahui respon dan tanggapan siswa terhadap komponen dan pelaksanaan pembelajaran dengan pendekatan EEK. Berdasarkan pengamatan saat pembelajaran diperoleh hasil bahwa: i) sebagian besar siswa memperhatikan informasi dan menjawab pertanyaan guru; ii) bersemangat saat diskusi mengerjakan LKS dan LLS; iii) Memperhatikan saat temannya presentasi dan guru memberikan klarifikasi (konfirmasi). Berdasarkan jawaban angket yang diberikan kepada siswa diperoleh hasil sebagai berikut: i) lebih dari $60 \%$ siswa menyatakan senang terhadap materi pelajaran, media pembelajaran, suasana pembelajaran, dan cara guru mengajar; ii) lebih dari $60 \%$ siswa menyatakan bahwa media pembelajaran dan cara guru mengajar adalah baru; iii) sebagian besar siswa tidak merasa terbebani oleh tugas-tugas yang diberikan guru dan aktivitas pembelajaran matematika menarik; iv) 85 , 3\% berminat apabila kegiatan pembelajaran selanjutnya menggunakan cara pembelajaran yang telah diikuti dan $100 \%$ siswa menyatakan bahwa matematika bermanfaat dalam kehidupan. Dapat disimpulkan bahwa siswa kelas IX di sebuah SMP yang belokasi di Mataram memberikan respon dan tanggapan yang baik terhadap komponen dan pelaksanaan pembelajaran dengan pendekatan EEK.
\end{abstract}

Kata Kunci: EEK; LKS; LLS

Cara Mengutip

Sripatmi, S., \& Ningsih, R.W. Respon dan tanggapan siswa terhadap komponen dan kegiatan pembelajaran matematika menerapkan pendekatan EksplorasiElaborasi-Konfirmasi (EEK). Mandalika Mathematics and Education Journal, 2(1), 1-8. http://doi.org/10.29303/mandalika.v3i1.1776 


\section{PENDAHULUAN}

Kegiatan pembelajaran atau proses belajar-mengajar merupakan proses interaksi peserta didik dengan pendidik dan sumber belajar pada suatu lingkungan belajar. Pembelajaran tidak dapat berlangsung seketika, melainkan melalui tahap perencanaan, meliputi 3 tahap, yaitu perancangan, pelaksanaan, serta evaluasi dan refleksi. Perencanaan pembelajaran dilakukan untuk mendapatkan strategi pembelajaran yang tepat agar diperoleh hasil belajar yang optimal sesuai dengan tujuan belajar. Pelaksanaan pembelajaran merupakan implementasi dari perencanaan pembelajaran dan harus dapat diukur atau dievaluasi keberhasilannya (Gülten, 2013; Saad et al., 2010). Keberhasilan kegitan pembelajaran antara lain ditentukan oleh pemahaman karakteristik isi materi pelajaran, karakteristik siswa, dan proses pembelajarannya sendiri. Karakteristik siswa adalah seluruh latar belakang yang dibawa ketika hadir di kelas sebelum pembelajaran dimulai.

Tingkat kualitas pembelajaran dapat diperlihatkan oleh tingginya keterlibatan peserta didik dalam pembelajaran, komunikasi antara guru dan peserta didik, serta komunikasi antar peserta didik dalam rangka menemukan konsep-konsep atau menyelesaikan masalah (Gülten, 2013; Saad et al., 2010). Salah satu cara yang dapat membantu guru dalam upaya meningkatkan kualitas pembelajaran adalah dengan penerapan model atau strategi pembelajaran yang tidak semata - mata hanya kegiatan guru mengajar, tetapi menitik beratkan pada aktivitas peserta didik, dan bukan hanya guru yang selalu aktif memberikan/menjelaskan pelajaran, guru membantu peserta didik jika memperoleh kesulitan, membimbing diskusi agar mampu membuat kesimpulan yang benar. Hal ini sesuai dengan karakteristik pelaksanaan pembelajaran yang diberlakukan di kurikulum tahun 2013. Keterampilan memilih strategi pembelajaran yang sesuai dengan karakteristik peserta didik dapat ditingkatkan dengan cara melaksanakan diskusi secara periodik dan rutin dengan teman sejawatnya.

Fakultas Keguruan dan Ilmu Pendidikan (FKIP) Universitas Mataram yang merupakan lembaga yang menghasilkan calon-calon pendidik. Agar calon-calon pendidik tersebut dapat menjadi para pendidik yang berkualitas dan siap menjalankan tugasnya sebagai pendidik yang profesional, FKIP selalu berusaha meningkatkan profesionalitas para dosennya melalui berbagai kegiatan. Salah satu kegiatan yang dilakukan di tahun 2018 ini adalah penugasan dosen di sekolah (PDS). Beberapa tujuan yang ingin dicapai dari kegiatan tersebut adalah: 1) terciptanya kemitraan sejati antara dosen LPTK dan guru Sekolah Mitra; 2) terciptanya pembelajaran yang bermutu dengan indikator: i) terciptanya iklim pembelajaran yang semakin baik; ii) perangkat pembelajaran yang semakin berkualitas; dan iii) meningkatnya prestasi belajar peserta didik (siswa). 


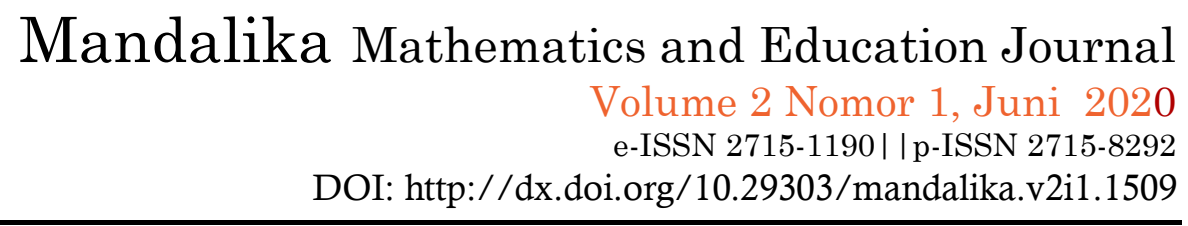

Sejak diberlakukannya K13, SMP lokasi penelitian secara bertahap telah menerapkan kurikulum tersebut. Salah satu ciri dari K13 adalah perangkat pembelajaran (RPP) dan pelaksanaan pembelajaran menggunakan pendekatan Scientific dengan tahapan pembelajaran mengedepankan $5 \mathrm{M}$, yaitu: Mengamati - Menanya - Mengekplorasi Mengasosiasi - Mengomunikasikan. Berdasarkan hasil observasi dan pembicarakan dengan guru-guru matematika di awal kegiatan PDS diperoleh hasil sebagai berikut: i) untuk perangkat pembelajaran matematika dengan pendekatan scientific banyak contoh-contoh yang di download atau diakses di internet; ii) tidak semua tahapan pembelajaran dengan pendekatan scientific tersebut mudah atau dapat diimplementasikan saat pembelajaran matematika di kelas. Hal ini bisa dimengerti, karena memang tidak ada satu pendekatan pembelajaran yang cocok digunakan untuk setiap situasi dan kondisi. Ada beberapa hal yang harus diperhatikan dalam menetapkan pendekatan pembelajaran yang akan diterapkan pada pembelajaran di kelas, antara lain karakteristik materi/topik, karakteristik siswa, dan ketersedian fasilitas untuk pelaksanaan pembelajaran. Oleh karenanya pada kegiatan PDS, disepakati penyusunan perangkat dan pelaksanaan pembelajaran dengan menggunakan pendekatan Eksplorasi - Elaborasi - Konfirmasi dengan harapan tersusunnya perangkat pembelajaran yang semakin berkualitas yang dapat menciptanya iklim pembelajaran yang semakin baik.

Dalam Kamus Besar Bahasa Indonesia Daring, eksplorasi diartikan bentuk penjelajahan dengan tujuan memperoleh pengetahuan lebih banyak atau kegiatan untuk memperoleh pengalaman baru dari situasi yang baru (Pusat Bahasa, 2010). Sedangkan Elaborasi diartikan menggarap atau mengerjakan secara cermat dan tekun. Konfirmasi diartikan penegasan, pengesahan atau pembenaran. Pada bagian eksplorasi, peserta didik difasilitasi untuk memperoleh pengetahuan dan keterampilan dan mengembangkan sikap melalui pembelajaran berpusat pada siswa. Aktivitas eksplorasi ini membawa siswa untuk berpikir kritis dan kreatif (Falconer et al., 2018). Kemudian bagian elaborasi, peserta didik diberi peluang untuk memperoleh pengetahuan dan keterampilan serta sikap lebih lanjut melalui sumber-sumber dan kegiatan-kegiatan pembelajaran lainnya sehingga pengetahuan, keterampilan, dan sikap peserta didik lebih luas dan mendalam. Pada akhirnya di bagian konfirmasi, peserta didik memperoleh umpan balik atas kebenaran, kelayakan, atau keberterimaan dari pengetahuan, keterampilan dan sikap yang diperolehnya. Tahapan ini sangat penting, karena masukan dari guru akan membantu siswa untuk mengkonstruksi pengetahuannya dengan maksimal (Gita \& Apsari, 2018).

Aktivitas eksplorasi ini membawa siswa untuk berpikir kritis dan kreatif. Costa dan Ennis (dalam Suryadi \& Herman, 2008) menyatakan bahwa berpikir kritis merupakan suatu proses penggunaan kemampuan berpikir secara efektif yang dapat membantu seseorang untuk membuat, mengevaluasi, dan mengambil suatu keputusan. Berpikir 


\section{Mandalika Mathematics and Education Journal \\ Volume 2 Nomor 1, Juni 2020 \\ e-ISSN 2715-1190 | p-ISSN 2715-8292 \\ DOI: http://dx.doi.org/10.29303/mandalika.v2i1.1509}

kreatif merupakan kemampuan untuk mengungkap hubungan-hubungan baru, melihat sesuatu dari sudut pandang baru, dan membentuk kombinasi dari konsep-konsep yang sudah dikuasai sebelumnya (Suyitno, 2004). Evans menyatakan bahwa kreativitas tidak dapat muncul karena pesanan, tetapi ide-ide kreatif biasanya muncul karena adanya interaksi dengan lingkungan atau stimulasi eksternal.

\section{METODE}

Metode penelitian ini adalah survey yang bertujuan untuk mengetahui tanggapan siswa terkait dengan pelaksanaan pembelajaran dengan pendekatan EEK. Lokasi penelitian adalah di kelas IX di sebuah SMP yang berlokasi di Mataram. Pengumpulan data dilakukan dengan menggunakan angket respons dan lembar observasi. Data dianalisis dengan menggunakan metode deskriptif kuantitatif.

\section{HASIL DAN PEMBAHASAN}

Perangkat pembelajaran dengan pendekatan EEK yang tersusun sebelum diimplementasikan di kegiatan pembelajaran dikonsulatasikan sekaligus dinilai oleh guru mitra dengan menggunakan Instrumen Penilaian Perencanaan Pembelajaran (IPKG-1), dan diperoleh hasil pada Tabel 1 berikut.

Tabel 1: Hasil penilaian Perencanaan Pembelajaran

\begin{tabular}{clcc}
\hline \multirow{2}{*}{ No } & \multicolumn{1}{c}{ Aspek yang dinilai } & \multicolumn{2}{c}{ Skor } \\
\cline { 3 - 4 } 1. & Kesesuaian antar kompetensi dasar dari KI1, KI2, KI3, dan KI4 & 5 & 5 \\
\hline 2. & $\begin{array}{l}\text { Kesesuaian rumusan indikator pencapaian kompetensi dasar } \\
\text { (dari KI1, KI2, KI3, dan KI4) yang akan dicapai. }\end{array}$ & 5 & 5 \\
\hline 3. & $\begin{array}{l}\text { Kesesuaian perumusan tujuan pembelajaran dengan indikator } \\
\text { pencapaian kompetensi }\end{array}$ & 4 & 5 \\
\hline 4. & $\begin{array}{l}\text { Kesesuaian materi pembelajaran dengan indikator dan } \\
\text { kompetensi dasar yang akan dicapai }\end{array}$ & 5 & 5 \\
\hline 5. & Kejelasan dan urutan materi ajar & 5 & 5 \\
\hline 6. & $\begin{array}{l}\text { Kesesuaian strategi pembelajaran (metode dan pendekatan) } \\
\text { dengan tujuan pembelajaran dan materi ajar }\end{array}$ & 5 & 5 \\
\hline 7. & $\begin{array}{l}\text { Kesesuaian strategi pembelajaran dengan karakteristik peserta } \\
\text { didik }\end{array}$ & 4 & 4 \\
\hline 8. & $\begin{array}{l}\text { Kejelasan skenario pembelajaran (langkah-langkah kegiatan } \\
\text { pembelajaran) dengan tujuan yang akan dicapai }\end{array}$ & 5 & 5 \\
\hline & $\begin{array}{l}\text { Skenario pembelajaran (langkah-langkah kegiatan } \\
\text { pembelajaran) menggambarkan active learning dan } \\
\text { mencerminkan scientific learning }\end{array}$ & 5 & 5 \\
10. & Ketepatan kegiatan penutup dalam pembelajaran & 5 & 5 \\
\hline 11. & $\begin{array}{l}\text { Penilaian mencakup aspek-aspek kompetensi dasar dari KI1, } \\
\text { KI2, KI3, dan KI4 yang harus dicapai }\end{array}$ & 4 & 4 \\
\hline 12. & $\begin{array}{l}\text { Kesesuaian teknik penilaian dengan indikator/kompetensi yang } \\
\text { akan dicapai }\end{array}$ & 4 & 4 \\
\hline
\end{tabular}




\begin{tabular}{cccc}
\hline 13. & Kelengkapan perangkat penilaian (soal, kunci, rubrik penilaian) & 4 & 4 \\
\hline 14. & Keterpaduan dan kesinkronan antar komponen dalam RPP & 5 & 5 \\
\hline Skor Total Perolehan & 65 & 66 \\
\hline Nilai = Skor Total Perolehan x 100 & 92,8 & 94,3
\end{tabular}

Skor Maks. (70)

Catatan: RPP 1 Bilangan Berpangkat dan Bentuk Akar, dan RPP 2 Persamaan Kuadrat. Dari Tabel 1 di atas terlihat bahwa perangkat pembelajaran yang akan diimplementasikan pada pembelajaran dalam berkatagori sangat baik.

Kualitas pelaksanaan pembelajaran dan respon siswa kelas IX di sebuah SMP di Mataram terhadap pelaksanaan pembelajar diperoleh melalui pengamatan saat pembelajaran oleh guru mitra dengan menggunakan Instrumen Penilaian Pelaksanaan Pembelajaran (IPKG-2). Rata-rata penilaian guru mitra terhadap pelaksanaan pembelajaran disajikan pada Tabel 2 berikut:

Tabel 2. Hasil penilaian Pelaksanaan Pembelajaran.

\begin{tabular}{|c|c|c|}
\hline No & Kegiatan dan Aspek yang diamati & Rata-rata skor \\
\hline A & Pendahuluan & \\
\hline 1 & Apersepsi dan Motivasi & 5 \\
\hline 2 & Penyampaian Kompetensi dan Rencana Kegiatan & 5 \\
\hline B & Inti & \\
\hline 1 & Penguasaan Materi Pelajaran & 5 \\
\hline 2 & Penerapan Strategi Pembelajaran yang Mendidik & 4,85 \\
\hline 3 & Penerapan Strategi yang mendukung berfikir kritis dan kreatif & 4,85 \\
\hline 4 & Pemanfaatan Sumber Belajar/Media dalam Pembelajaran & 5 \\
\hline 5 & Pelibatan Peserta Didik dalam Pembelajaran & 4,8 \\
\hline 6 & Penggunaan Bahasa yang Benar dan Tepat dalam Pembelajaran & 5 \\
\hline $\mathbf{C}$ & Penutup & 5 \\
\hline & Total Skor Perolehan & 44,5 \\
\hline & Nilai $=\frac{\text { Skor Total Perolehan }}{\text { Skor Maks. }(45)} 100$ & 98,8 \\
\hline
\end{tabular}

Dari Tabel 2 terlihat bahwa pelaksanaan pembelajaran materi bilangan berpangkat dan bentuk akar, serta persamaan kuadrat berkatagori sangat baik.

Selanjutnya, berdasarkan pengamatan guru mitra saat pembelajaran terekam respon siswa terhadap pelaksanaan pembelajaran sangat baik, hal ini ditunjukkan oleh indikator berikut: i) siswa memperhatikan informasi dan menjawab/merespon pertanyaan guru, ii) siswa bersemangat saat diskusi mengerjakan LKS dan LLS, iii) siswa memperhatikan saat temannya presentasi dan guru memberikan klarifikasi/konfirmasi. Berikut beberapa dokumentasi yang menunjukkan situasi pembelajaran.

Untuk mengetahui sikap dan tanggapan siswa kelas IX di sebuah SMP di Mataram terhadap komponen dan kegiatan pembelajaran dengan pendekatan EEK, di akhir 
Mandalika Mathematics and Education Journal

Volume 2 Nomor 1, Juni 2020

e-ISSN 2715-1190 | | p-ISSN 2715-8292

DOI: http://dx.doi.org/10.29303/mandalika.v2i1.1509

pelaksanaan kegiatan PDS siswa diminta mengisi angket, dan diperoleh hasil sebagai berikut. 


\section{Mandalika Mathematics and Education Journal \\ Volume 2 Nomor 1, Juni 2020 \\ e-ISSN 2715-1190 | | p-ISSN 2715-8292 \\ DOI: http://dx.doi.org/10.29303/mandalika.v2i1.1509}

1. Sikap siswa terhadap komponen pembelajaran, seperti pada tabel 3

Tabel. 3. Sikap terhadap komponen pembelajaran

\begin{tabular}{lcc}
\hline \multicolumn{1}{c}{ Komponen } & Senang & Tidak Senang \\
\hline Materi Pembelajaran & $91,2 \%$ & $8,8 \%$ \\
\hline LKS dan LLS (Media) & $91,2 \%$ & $8,8 \%$ \\
\hline Suasana belajar di kelas & $61,8 \%$ & $38,2 \%$ \\
\hline Cara guru mengajar & $67,6 \%$ & $32,4 \%$ \\
\hline
\end{tabular}

Berdasarkan Tabel 3 dia atas, sebagian besar siswa bersikap senang terhadap komponen materi dan media pembelajaran yang disampaikan guru, dan lebih dari setengah banyaknya siswa di kelas IX di sebuah SMP di Mataram juga menyatakan senang terhadap suasana belajar di kelas dan cara guru mengajar.

Beberapa alasan yang diungkapkan oleh siswa mengapa mereka memberikan jawaban senang atau tidak senang terhadap masing-masing komponen pembelajaran tersebut sebagai berikut: i) senang dengan materi pembelajaran karena materi mudah dipahami, harus senang bila tidak nanti nilainya jelek, menyukai matematika, tidak senang dengan dengan materi pembelajaran karena tidak mengerti dengan materi yang disampaikan; ii) senang dengan media pembelajaran (LKS dan LLS) karena ada bimbingan/petunjuk cara mengerjakan LKS dan LLS, suka mengerjakan soal-soal di LLS, masalahnya dan soal-soal tidak terlalu sulit, tidak senang dengan media pembelajaran (LKS dan LLS) karena idak mengerti cara mengerjakan masalah di LKS dan soal-soal di LLS; iii) senang dengan suasana belajar di kelas karena pembelajaran sangat bersemangat, tidak senang dengan suasana belajar di kelas karena ada siswa yang ribut, beberapa teman ribut jadi suasana belajar tidak enak, sebagian besar siswa putra suka ribut; iv) senang dengan cara guru mengajar karena mudah dipahami, apabila ada siswa yang tidak dimengerti guru menjelaskan lagi sampai siswa mengerti, dapat memahami materi yang diberikan, memudahkan siswa dalam memahami materi, banyak materi terdahulu yang diingatkan lagi, menggunakan cara yang mudah mengerti, tidak senang dengan cara guru mengajar karena mengajarnya terlalu cepat, tidak mengerti yang diajarkan, jam istirahat dikurangi, banyak rumus-rumusnya dan terlalu rumit.

Berdasarkan rekapitulasi angket yang terkumpul diperoleh informasi bahwa siswa yang senang terhadap komponen materi pembelajaran senang juga terhadap komponen media pembelajar yang digunakan. Beberapa siswa yang senang terhadap materi pembelajaran tidak senang dengan suasana pembelajaran. Dan semua siswa yang tidak senang terhadap materi dan media pembelajaran tidak senang dengan cara guru mengajar, hal ini berarti cara guru mengajar belum mampu memotivasi siswa yang tidak menyukai pelajaran matematika menjadi menyukai dan serius mengikuti pembelajaran matematika. 


\section{Mandalika Mathematics and Education Journal \\ Volume 2 Nomor 1, Juni 2020 \\ e-ISSN 2715-1190 | | p-ISSN 2715-8292 \\ DOI: http://dx.doi.org/10.29303/mandalika.v2i1.1509}

2. Tanggapan siswa terhadap komponen, seperti pada Tabel 4

Tabel. 4. Tanggapan siswa terhadap komponen pembelajaran

\begin{tabular}{lcc}
\hline Komponen & Baru & Tidak Baru \\
\hline Materi Pembelajaran & $20,6 \%$ & $79,4 \%$ \\
LKS dan LLS (Media) & $61,8 \%$ & $38,2 \%$ \\
Suasana belajar di kelas & $23,5 \%$ & $76,5 \%$ \\
Cara guru mengajar & $64,7 \%$ & $35,3 \%$ \\
\hline
\end{tabular}

Berdasarkan Tabel 4 dia atas, lebih dari setengah banyak siswa kelas IX di SMP yang berlokasi di Mataram menyatakan bahwa komponen materi pembelajaran dan suasana belajar di kelas bukan hal baru, sedangkan untuk komponen media pembelajaran dan cara guru mengajar lebih dari setengah banyaknya siswa di kelas IX di SMP yang berlokasi di Mataram menyatakan sesuatu yang baru.

Beberapa alasan yang diungkapkan oleh siswa mengapa mereka memberikan jawaban baru atau tidak baru terhadap masing-masing komponen pembelajaran tersebut adalah sebagai berikut: i) materi pembelajaran (bilangan berpangkat dan bentuk akar serta persamaan kuadrat) bukan materi baru karena materi tersebut sudah pernah dipelajari di tempat mereka les atau belajar privat, dan yang menyatakan materi tersebut baru karena baru mendapatkan di kelas IX; ii) suasana pembelajaran bukan hal baru karena suasana belajar sama dengan di kelas VII - VIII, siswa putra sering ribut, terlalu sering suasana seperti itu, suasana memang seperti ini sebelumnya, serta alasan beberapa siswa yang menyatakan suasana belajar baru karena guru baru maka suasana baru, guru berbeda cara mengajarnya, cara guru mengajar menyenangkan; iii) media pembelajaran merupakan hal baru karena setiap LKS dan LLS yang diberikan menarik dan mendapatkan cara menemukan rumus, mendapatkan soal-soal baru yang lebih menantang, jarang menggunakan LKS dan LLS pada pembelajaran sebelumnya; iv) guru mengajar dengan cara baru karena baru ketemu di kelas IX, mengajar dengan cara yang asyik, enak, santai dan menggunakan cara yang mudah dimengerti, beberapa siswa yang menyatakan cara guru mengajar tidak baru karena sehabis dijelaskan kita diberikan tugas, sama seperti tugas sama seperti guru lainnya.

Berdasarkan uraian di atas, dalam kegiatan pembelajaran diharapkan guru berusaha menyiapkan berbagai media dan pendekatan pembelajaran yang bervariasi agar tercipta suasana pembelajaran yang baru dan menarik minat siswa.

3. Tanggapan siswa terhadap aktivitas belajar matematika di kelas dan di luar kelas, seperti pada Tabel 5 
Tabel. 5. Tanggapan siswa terhadap aktivitas belajar matematika di kelas dan di luar kelas

\begin{tabular}{lcc}
\hline \multicolumn{1}{c}{ Komponen } & Ya & Tidak \\
\hline $\begin{array}{l}\text { Kalian merasa terbebani terhadap tugas- } \\
\text { tugas yang diberikan guru. }\end{array}$ & $20,6 \%$ & $79,4 \%$ \\
\hline $\begin{array}{l}\text { Menurut kalian aktivitas belajar } \\
\text { matematika menarik. }\end{array}$ & $79,4 \%$ & $20,6 \%$ \\
\hline
\end{tabular}

Berdasarkan Tabel 5 di atas sebagian besar siswa menyatakan tidak merasa terbebani dengan tugas-tugas yang diberikan guru saat pembelajaran matematika di kelas maupun tugas rumah yang diberikan. Sebagian besar siswa juga menyatakan aktivitas belajar matematika menarik. Adapun berdasarkan rekapitulasi angket yang terkumpul diperoleh hasil bahwa siswa yang menyatakan aktivitas belajar matematika tidak menarik mereka merasa terbebani dengan tugas-tugas matematika yang diberikan oleh guru.

Beberapa alasan siswa yang merasa terbebani dengan tugas-tugas matematika yang diberikan adalah: pulang sekolah saya harus les sana-sini dan lelah kalau tugas banyak, kalau banyak tugas tubuh yang letih tambah tertekan. Beberapa alasan siswa yang merasa tidak terbebani dengan tugas-tugas matematika yang diberikan adalah: dengan tugas bisa mengasah otak, tidak banyak tugas yang diberikan, melatih kemampuan dalam mengerjakan soal2, ada tugas ada kerjaan sehingga tidak banyak main-main. Beberapa alasan siswa yang menyatakan aktivitas belajar matematika menarik adalah: bisa tahu hal-hal yang baru, karena suka matematika, banyak materi di balik matematika, cara mengajar gurunya tidak membosankan, menambah wawasan siswa, matematika memiliki rumus yang menarik untuk dipahami, setiap materi matematika menyenangkan, berguna untuk masa depan. Alasan siswa yang menyatakan aktivitas belajar matematika tidak menarik adalah: karena lebih suka pelajaran penjas, gurunya terlalu fokus mengajarnya dan tidak ngajak bermain, tidak menyukai matematika.

4. Sebanyak 85,3 \% siswa kelas IX di SMP yang berlokasi di Mataram menyatakan berminat apabila kegiatan pembelajaran matematika selanjutnya menggunakan cara pembelajaran yang telah diikuti (EEK), dan beberapa alasan yang diungkapkan adalah: tertarik/suka pada matematika, kewajiban pelajar harus belajar sungguh2, supaya nilai matematika saya lebih baik, menyenangkan, mendapatkan pengalaman/cara baru, senang dengan penjelasannya seru, ingin bisa matematika. $14,7 \%$ siswa menyatakan tidak berminat apabila kegiatan pembelajaran matematika selanjutnya menggunakan cara pembelajaran yang telah diikuti, karena tidak menyukai pelajaran matematika, bosan dengan pemberian materi terus menerus, yang diajarkan terlalu rumit. 


\section{Mandalika Mathematics and Education Journal \\ Volume 2 Nomor 1, Juni 2020 \\ e-ISSN 2715-1190 | | p-ISSN 2715-8292 \\ DOI: http://dx.doi.org/10.29303/mandalika.v2i1.1509}

5. Semua siswa menyatakan bahwa matematika bermanfaat dalam kehidupan. Berikut beberapa alasan yang diungkapkan siswa kenapa matematika bermanfaat dalam kehidupan, yaitu : i) pokoknya matematika bermanfat, tapi tidak tahu apa alasannya, ii) berguna untuk kegiatan jual-beli, iii) dalam kegiatan sehari-hari pasti ada hitunghitungan, iv) suatu saat pasti akan sangat bermanfaat bagi saya, v) matematika sering dipakai di pelajaran lainnya, vi) setiap kehidupan pasti berkaitan dengan matematika, vii) supaya tidak gampang dibodohi-bodohi orang tentang hitung-hitungan, viii) matematika sangat diperlukan untuk pengusaha. Temuan ini sejalan dengan penelitian sebelumnya, dimana apresiasi matematika yang dimiliki siswa tergolong cukup baik (Mann, 2006).

Berdasarkan uraian di atas terungkap bahwa meskipun siswa menyadari bahwa matematika bermanfaat dalam kehidupannya belum tentu mampu memotivasinya untuk menyukai dan serius dalam kegiatan pembelajaran matematika, bahwa ada yang merasa terbebani dengan tugas-tugas yang diberikan. Untuk itu salah satu upaya yang dapat dilakukan adalah dengan memberikan penugasan yang realistik seperti yang ditunjukkan oleh penelitian terkait dengan penggunaan Pendidikan Matematika Realistik Indonesia dalam pembelajaran (Apsari, Putri, et al., 2020; Apsari, Sariyasa, et al., 2020; Revina \& Leung, 2019; Sembiring et al., 2008; Shanty et al., 2011).

\section{PENUTUP}

Berdasarkan pembahasan di atas dapat disimpulkan sebagai berikut. Siswa kelas IX di SMP yang berlokasi di Mataram tahun ajaran 2018-2019 memberikan respon sangat baik pada pelaksanaan pembelajaran matematika dengan pendekatan EEK, dengan indikator sebagai berikut: i) siswa memperhatikan informasi dan menjawab/merespon pertanyaan guru, ii) siswa bersemangat saat diskusi mengerjakan LKS dan LLS, iii) siswa memperhatikan saat temannya presentasi dan guru memberikan klarifikasi/konfirmasi.

Sikap dan tanggapan siswa terhadap komponen dan kegiatan pembelajaran dengan pendekatan EEK baik, dengan indikator sebagian besar siswa menyatakan i) senang dengan suasana pembelajaran di kelas, cara guru mengajar, dan media pembelajaran yang digunakan; ii) bahwa media pembelajaran yang digunakan dan cara mengajar guru merupakan hal baru; iii) aktivitas belajar matematika menarik dan tidak merasa terbebani dengan tugas-tugas yang diberikan guru; iv) berminat apabila kegiatan pembelajaran matematika selanjutnya menggunakan cara pembelajaran yang telah diikuti (EEK).

Merefleksi hasil penelitian ini dapat direkomendasikan bagi guru-guru matematika untuk menyusun rencana dan melaksanakan pembelajaran dengan menggunakan pendekatan dan medote pembelajaran yang beragaram, salah satunya pendekatan EEK 
dengan memperhatikan karakteristik materi/topik pelajaran dan siswa yang belajar, serta menggunakan media pembelajaran yang lebih bervariasi.

\section{REFERENSI}

Apsari, R. A., Putri, R. I. I., Sariyasa, Abels, M., \& Prayitno, S. (2020). Geometry representation to develop algebraic thinking: A recommendation for a pattern investigation in pre-algebra class. Journal on Mathematics Education, 11(1), 45-58. https://doi.org/10.22342/jme.11.1.9535.45-58

Apsari, R. A., Sariyasa, S., Putri, R. I. I., Gunawan, G., \& Prayitno, S. (2020). Understanding Students ' Transition from Arithmetic to Algebraic Thinking in the Pre-Algebraic Lesson Understanding Students ' Transition from Arithmetic to Algebraic Thinking in the PreAlgebraic Lesson. Journal of Physics: Conference Series, 1471, 1-7. https://doi.org/10.1088/1742-6596/1471/1/012056

Falconer, E. G., Cropley, D. H., \& Dollard, M. F. (2018). An Exploration of Creativity in Primary School Children. International Journal of Creativity and Problem Solving, 28(2), 7-25.

Gita, I. N., \& Apsari, R. A. (2018). Scaffolding in problem based learning to increase students' achievements in linear algebra. Journal of Physics: Conference Series, 1040(1). https://doi.org/10.1088/1742-6596/1040/1/012024

Gülten, A. Z. (2013). Am I Planning well? Teacher Trainees' Voices on Lesson Planning. Procedia - Social and Behavioral Sciences, 93(2010), 1409-1413. https://doi.org/10.1016/j.sbspro.2013.10.053

Mann, E. L. (2006). Creativity: The essence of mathematics. Journal for the Education of the Gifted, 30(2), 236-260. https://doi.org/10.4219/jeg-2006-264

Pusat Bahasa. (2010). Kamus Besar Bahasa Indonesia (KBBI) Daring.

Revina, S., \& Leung, F. K. S. (2019). Issues involved in the adoption of Realistic Mathematics Education in Indonesian culture. Compare, 00(00), 1-20. https://doi.org/10.1080/03057925.2019.1650636

Saad, A., Chung, P. W. H., \& Dawson, C. (2010). The development of Lesson Planning System based on case based reasoning (CBR) concept: The methodology. Proc. of the IADIS Int. Confs. - Informatics 2010, Wireless Applications and Computing 2010, Telecommunications, Networks and Systems 2010, Part of the MCCSIS 2010, March 2016, 231-234.

Sembiring, R. K., Hadi, S., \& Dolk, M. (2008). Reforming mathematics learning in Indonesian classrooms through RME. ZDM - International Journal on Mathematics Education, 40(6), 927-939. https://doi.org/10.1007/s11858-008-0125-9

Shanty, N. O., Hartono, Y., Putri, R. I. I., \& De Haan, D. (2011). Design research on mathematics education: Investigating the progress of Indonesian fifth grade students' learning on multiplication of fractions with natural numbers. Journal on Mathematics Education, 2(2), 147-162. https://doi.org/10.22342/jme.2.2.749.147-162

Suryadi, D., \& Herman, T. (2008). Eksplorasi Matematika Pembelajaran Pemecahan Masalah. Karya Duta Wahana.

Suyitno, A. (2004). Pemilihan Model-model Pembelajaran dan Penerapannya di Sekolah. Pendidikan Matematika FMIPA UNNES. 